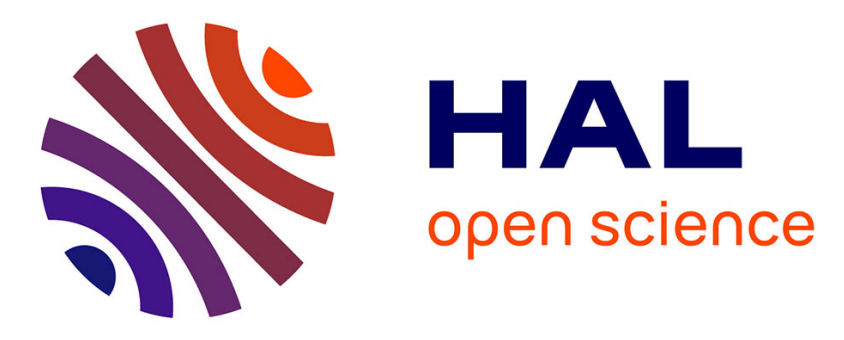

\title{
Aza-Piancatelli Cyclization as a Platform for the Preparation of Scaffolds of Natural Compounds: Application to the Total Synthesis of Bruceolline D
}

Lucile Marin, Guillaume Force, Vincent Gandon, Emmanuelle Schulz, David Lebøeuf

\section{To cite this version:}

Lucile Marin, Guillaume Force, Vincent Gandon, Emmanuelle Schulz, David Lebøeuf. Aza-Piancatelli Cyclization as a Platform for the Preparation of Scaffolds of Natural Compounds: Application to the Total Synthesis of Bruceolline D. European Journal of Organic Chemistry, 2020, 2020 (33), pp.53235328. 10.1002/ejoc.202000849 . hal-02990401

\section{HAL Id: hal-02990401 https://hal.science/hal-02990401}

Submitted on 19 Nov 2020

HAL is a multi-disciplinary open access archive for the deposit and dissemination of scientific research documents, whether they are published or not. The documents may come from teaching and research institutions in France or abroad, or from public or private research centers.
L'archive ouverte pluridisciplinaire HAL, est destinée au dépôt et à la diffusion de documents scientifiques de niveau recherche, publiés ou non, émanant des établissements d'enseignement et de recherche français ou étrangers, des laboratoires publics ou privés. 


\title{
Aza-Piancatelli Cyclization as a Platform for the Preparation of Scaffolds of Natural and Bioactive Compounds: Application to the Total Synthesis of Bruceolline D
}

\author{
Lucile Marin, ${ }^{[a]}$ Guillaume Force, ${ }^{[a]}$ Vincent Gandon, ${ }^{[a]}$ Emmanuelle Schulz, ${ }^{[a]}$ and David Leboeuf ${ }^{*[b]}$
}

\author{
[a] L. Marin, G. Force, Prof. Dr. V. Gandon, Dr. E. Schulz \\ Institut de Chimie Moléculaire et des Matériaux d'Orsay (ICMMO), CNRS UMR 8182 \\ Université Paris-Saclay \\ Bâtiment 420, 91405 Orsay, France. \\ [b] Dr. D. Leboeuf \\ Institut de Science et d'Ingénierie Supramoléculaires (ISIS), CNRS UMR 7006 \\ Université de Strasbourg \\ 8 allée Gaspard Monge, 67000 Strasbourg, France. \\ Email: dleboeuf@unistra.fr \\ Supporting information for this article is given via a link at the end of the document.((Please delete this text if not appropriate))
}

\begin{abstract}
The aza-Piancatelli cyclization is an appealing transformation for the synthesis of 4-aminocyclopentenone building blocks that could be then converted into bioactive aminocyclopentitols; however, while this approach appears promising total syntheses of natural products featuring the aza-Piancatelli cyclization as a key step are still unprecedented. Here, we disclose our in-depth investigations regarding this reaction in order to access highly complex structures representing the core of some bioactive molecules. The applicability of the cyclization was highlighted by the 3-step total synthesis of bruceolline D. Thus, we anticipate that this work will lay the ground for further applications in the synthesis.
\end{abstract}

In the last decade, the aza-Piancatelli cyclization has garnered a growing interest because it enables a rapid and efficient pathway to 4-aminocyclopententenone derivatives from biomass-derived furan feedstocks. ${ }^{[1]}$ In general, this reaction represents a direct entry to aminocyclitol scaffolds that can be found in numerous bioactive and natural products (Scheme 1). ${ }^{[2]}$ They include pactamycin (antibiotic, antiprotozoal and antiproliferative properties), ${ }^{[3]}$ jogyamycin (antiprotozoal) ${ }_{2}^{[4]}$ peramivir (antiviral), ${ }_{1}^{[5]}$ and trehazolin (glycosidase inhibitor). ${ }^{[6]}$ Furthermore, this reaction may also provide a straightforward access to more complex polycyclic targets such as cephalotaxine,,$^{[7]}$ bruceolline $D^{[8]}$ and yuehchukene,,$^{[9]}$ which embed a cyclopenta[b]indole unit, or gracilamine. ${ }^{[10]}$ Since the pioneering work of Denisov et al. ${ }^{[11]}$ and Read de Alaniz group, ${ }^{[12]}$ we and others have directed efforts towards the preparation of even more densely functionalized targets using the aza-Piancatelli cyclization as a cornerstone. ${ }^{[13]}$ For instance, we implemented new strategies for the synthesis of polycyclic structures such as cyclopenta[b]pyrroles, ${ }^{[14]}$ cyclopenta[b]piperazinones ${ }^{[15]}$ and tetrahydrobenzo[b]azepines ${ }^{[16]}$ by pairing the aza-Piancatelli cyclization with a second key transformation, such as hydroamination, annulation or Michael addition. In turn, the studies related to the influence of the substitution pattern of the furan ring on the reactivity has been underexplored. ${ }^{[17]}$ This issue is particularly critical when considering the compounds mentioned above, which bear a multitude of additional functional groups, including heteroatoms on the cyclopentane ring. As a result, the question remains whether the aza-Piancatelli cyclization could be truly useful for the synthesis of such natural and bioactive molecules. In this context, we disclose herein our recent findings to increase the synthetic utility of this reaction by developing (1) a general synthetic approach to install several key functionalities of pactamycin, jogyamycin and peramivir, (2) a simple method to build the cyclopenta[b]indole moiety, which was highlighted by the total synthesis of bruceolline D, and finally (3) an azaPiancatelli/Diels-Alder/fragmentation reaction sequence to access frameworks of interest. Besides, we provide an overview on the scope and limitations of this reaction, demonstrating that the presence of heteroatoms on the furan ring does not impede the reactivity.

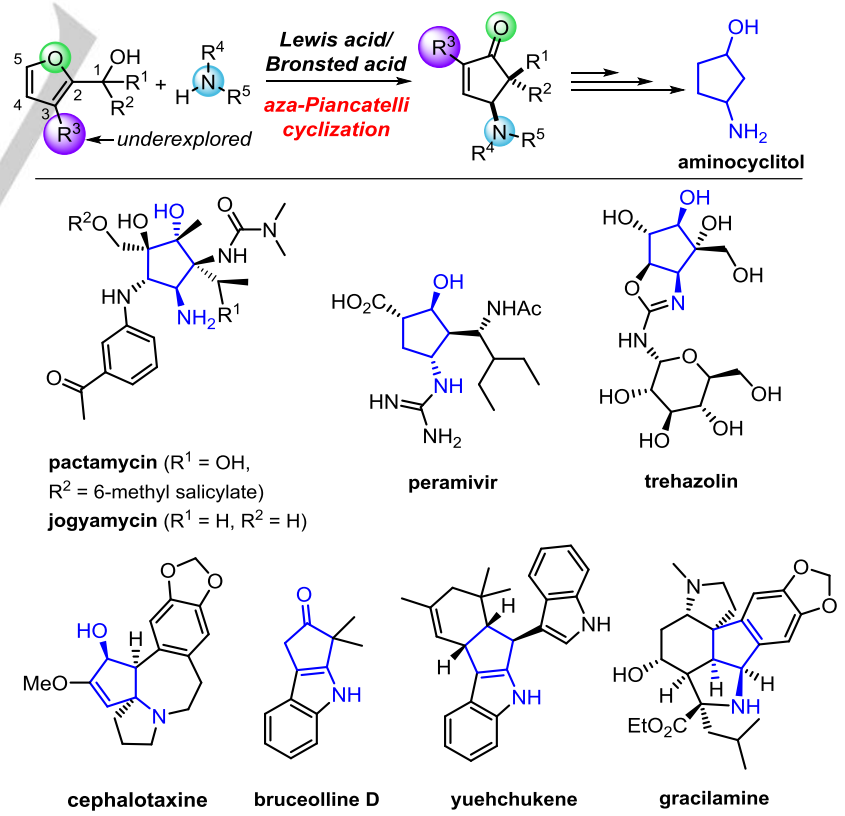

Scheme 1. Aza-Piancatelli cyclization as a platform for natural and bioactive compounds.

In our initial investigations, we focused on a general route to access the core of pactamycin, jogyamycin and peramivir (Scheme 2). We noticed that all their structures have in common the presence of an oxygen functionality (hydroxymethyl or carboxylic acid) at the same position. In order to perform the aza- 
Piancatelli cyclization, our first task was to prepare the 2furylcarbinol precursors, which involved the installation of the desired functional groups at the position $\mathrm{C} 3$ of the furan ring. We hypothesized that the simplest way to achieve this goal would be to start from the inexpensive 3-furoic acid $1(\sim 2 € / g)$. This strategy brings two advantages: (1) the key functional group or its direct precursor would be already present, and (2) it is well-documented that the carboxylic acid can serve as a directing group for the regioselective alkylation of furans with aldehydes to rapidly introduce the carbinol moiety. ${ }^{[18]}$ Following this approach, we obtained the 2-furylcarbinol intermediates 3 , which were engaged in the next step without further purification. Then, we conducted the selective methylation of the carboxylic acid upon treatment with trimethylsilyldiazomethane to afford the corresponding esters 4 in good to excellent yields over two steps (up to 97\%). Finally, the reduction of the ester with $\mathrm{LiAlH}_{4}$ and the subsequent protection of the primary alcohol formed 5 with tertbutyldimethylsilyl chloride (TBSCl) furnished the targeted precursors 6 . The protection of this alcohol was required to preclude any direct dehydrative nucleophilic substitution during the reaction.

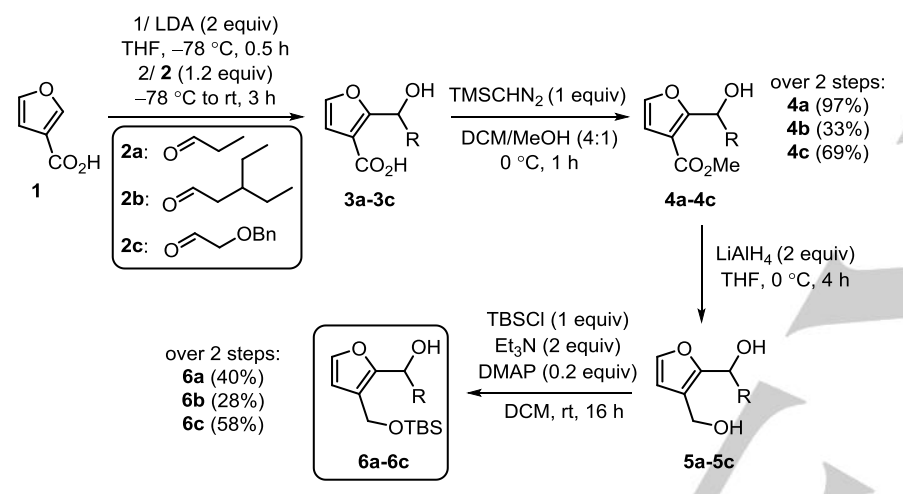

Scheme 2. Preparation of 2-furylcarbinol precursors.

With these precursors in hand, we evaluated their reactivity in the aza-Piancatelli cyclization (Scheme 3 ). During our previous studies, we developed an efficient promoter system, combining three key components: $\mathrm{Ca}\left(\mathrm{NTf}_{2}\right)_{2}$ as a catalyst with $n \mathrm{Bu}_{4} \mathrm{NPF}_{6}$ as an additive in hexafluoroisopropanol (HFIP) as a solvent. ${ }^{[19]}$ This catalytic system allows to work under milder reaction conditions than classic ones, and enables to trigger the reaction with less reactive substrates, including anilines bearing strong electrondonating groups, due to the remarkable ability of HFIP to stabilize carbocation species, to strongly donate hydrogen bonds, in addition to its low nucleophilicity. ${ }^{[20]}$ First, we examined the reaction between $6 \mathbf{a}$ and a series of amines $(\mathbf{7 a - 7 c})$. In each case, the 4-aminocyclopentenone was obtained in high yield (up to $95 \%$ ), with most of the functionalities of jogyamycin being installed. In the same vein, we explored the reactivity of the precursors of peramivir. At the outset, we tested $\mathbf{3 b}$ and $\mathbf{3 c}$ with $p$-anisidine $\mathbf{7 a}$ under our standard reaction conditions. However, the presence of an electron-drawing group at the C3-position of the furan shutdown the reaction and deactivated completely the alcohol, which remained intact. On the other hand, in the case of the reaction for $\mathbf{6 b}$, the target product $\mathbf{8 b a}$ was formed and isolated in $97 \%$ yield. With a sight on peramivir, we also conducted the hydrogenation of the cyclopentenone to deliver 9 in $94 \%$ yield. Although the identification of the structure of 9 could not be confimred by NMR studies due to the overlap of the signals, NOESY NMR experiments pointed toward the correct arrangement of the substituents (see the Supporting Information for details). Lastly, precursor $6 c$ was subjected to the same reaction conditions with aniline $\mathbf{7 d}$. However, under these conditions, the reaction led only to the decomposition of the substrate. It might be caused by the presence of the benzyl ether that could be deprotected under the reaction conditions. ${ }^{[21]}$ Gratifyingly, switching solvent from HFIP to nitromethane produced compound $\mathbf{8 c d}$ in $78 \%$ yield, thereby offering an entry point to pactamycin and potential analogues. ${ }^{[22]}$

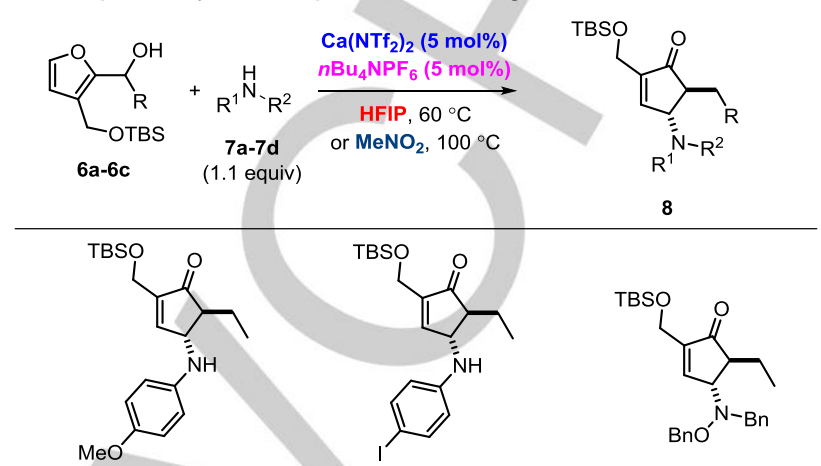

8aa $(95 \%$, HFIP, 1.5 h)

8 ab $(92 \%, \mathrm{HFIP}, 0.5 \mathrm{~h})$

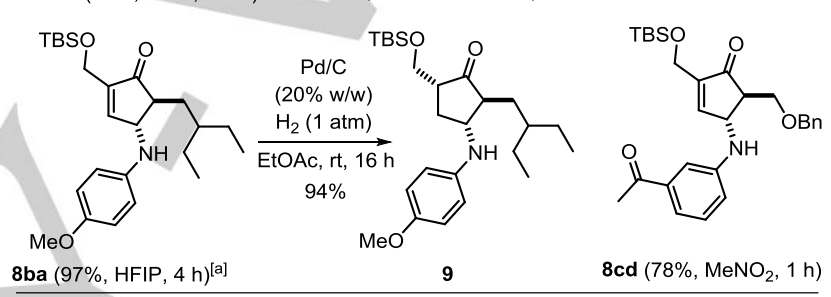

Scheme 3. Aza-Piancatelli cyclization of 2 -furylcarbinols $6 a-6 c$ with amines $7 a-$ 7d. Structure of 9 tentatively assigned. [a] $\mathbf{6 b}$ (1.2 equiv) and $7 \mathbf{a}$ (1 equiv).

Another issue that we addressed was the possibility to directly introduce heteroatoms such as oxygen for the synthesis of trehazolin and cephalotaxine or nitrogen for the synthesis of pactamycin and jogyamycin on the furan ring (Scheme 4). To assess such reactivity, we prepared model substrates bearing methoxy or azide functionalities that were easily introduced by direct nucleophilic substitution on 3-bromofuraldehyde, forming the products $6 \mathrm{~d}$-e in high yields. Importantly, in contrast with the case mentioned above with a strong electron-withdrawing group, the presence of a strong electron-donating renders the 2furylcarbinol highly reactive and, therefore, not compatible with the standard conditions (with HFIP). In turn, the reaction with nitromethane in place of HFIP provided $8 \mathbf{d b}$ in $70 \%$ yield. Besides, the excellent result obtained for the reaction of azide offers also a plausible alternative to the synthesis of pactamycin.
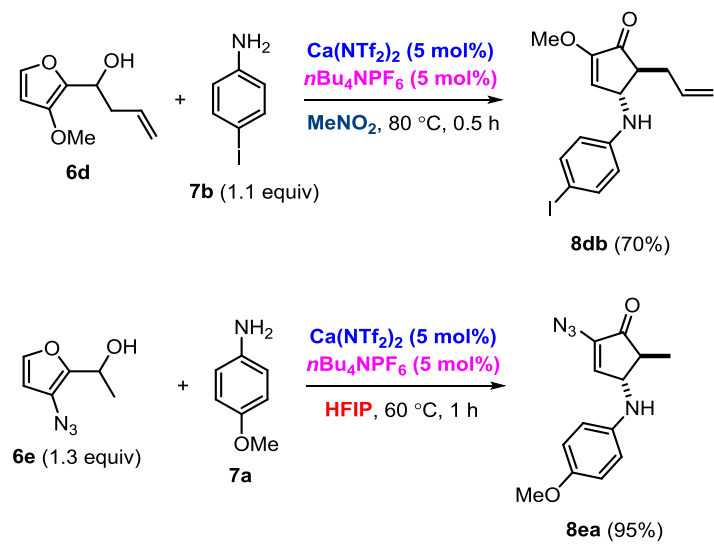

Scheme 4. Influence of the presence of heteroatoms on the aza-Piancatelli cyclization. 
Our second objective was to determine whether the azaPiancatelli could be used to generate cyclopenta[ $b]$ indole scaffolds. As a proof of concept, we explored the total synthesis of bruceolline D (Scheme 5). This molecule was isolated in 1994 by the group of Ohmoto from the root wood Brucea mollis Wall. var. tonkinensis Lecomte and is mostly employed in China for the treatment of malaria. ${ }^{[8]}$ To date, only three total syntheses were described for this molecule. ${ }^{[8 c-d]}$ Here, we envisioned an intramolecular aza-Piancatelli cyclization from precursor $\mathbf{1 1}$ to deliver bruceolline $\mathrm{D}$. This substrate was rapidly synthesized from commercially available methyl 4-bromofuran-2-carboxylate by addition of methyl Grignard reagent ( $90 \%$ yield) to the ester group and subsequent a Suzuki-Miyaura cross-coupling reaction with 2aminophenylboronic acid 7 e (42\% yield). However, independent of the solvent employed, the cyclization step did not occur. We only observed the decomposition of $\mathbf{1 1}$, which might suggest that the structure is too strained to allow the cyclization. Thus, we changed our approach by performing the aza-Piancatelli cyclization first, which was followed by a Suzuki-Miyaura crosscoupling. First, we studied the cyclization with a model substrate $6 f$ and aniline $\mathbf{7 b}$ as a nucleophile. We noticed that the solvent was critical for this transformation because the dehydration of the alcohol occured easily in HFIP or nitromethane, presumably due to the presence of both methyl groups. On the other hand, conducting the reaction in a solvent less prone to $\mathrm{H}$-bonding such as toluene provided the targeted 4-aminocyclopentenone $\mathbf{8 f b}$ in $66 \%$ yield. ${ }^{[23]}$ Next, we examined the reactivity of 2 -furylcarbinol 10 with both 2-aminophenylboronic acid $7 e$ and 2aminophenylboronic acid pinacol ester $\mathbf{7 f}$ in toluene. The reaction with the latter formed the cyclization product in higher yield $67 \%$ vs $40 \%$ ). Finally, a Suzuki-Miyaura cross-coupling reaction ${ }^{[24]}$ led to bruceolline D in $48 \%$ yield (3 steps, overall yield $29 \%$ ), demonstrating the synthetic utility of the aza-Piancatelli cyclization.
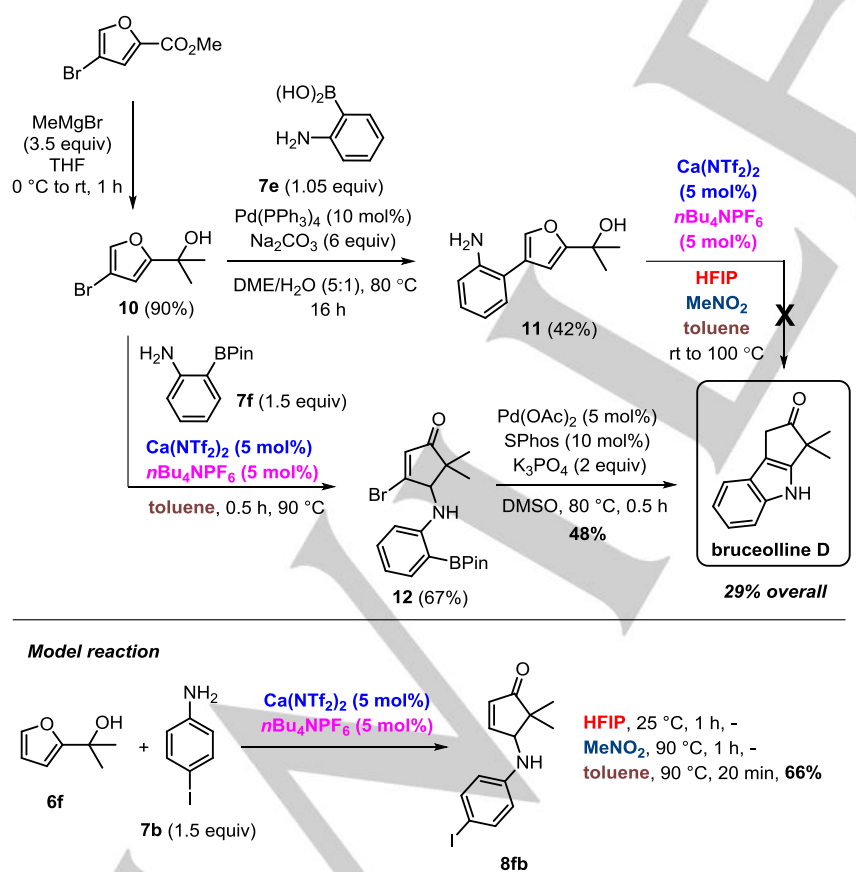

HFIP, $25^{\circ} \mathrm{C}, 1 \mathrm{~h}$, $\mathrm{MeNO}_{2}, 90^{\circ} \mathrm{C}, 1 \mathrm{~h}$, toluene, $90^{\circ} \mathrm{C}, 20 \mathrm{~min}, 66 \%$

8fb

Scheme 5. Total synthesis of bruceolline D.

Similarly, we sought to exploit the same strategy to access the framework of yuehchukene (Equation 1). While the cyclization reaction worked smoothly, without even requiring the utilization of $\mathrm{Ca}\left(\mathrm{NTf}_{2}\right)_{2}$ due to the intrinsic acidity of HFIP, all our attempts to achieve the Suzuki-Miyaura cross-coupling reaction failed. At this stage, we do not have specific explanation for this result. Although further optimization studies would be necessary to accomplish this sequence, the approach enabled the construction of the cyclopentane ring of yuehchukene.

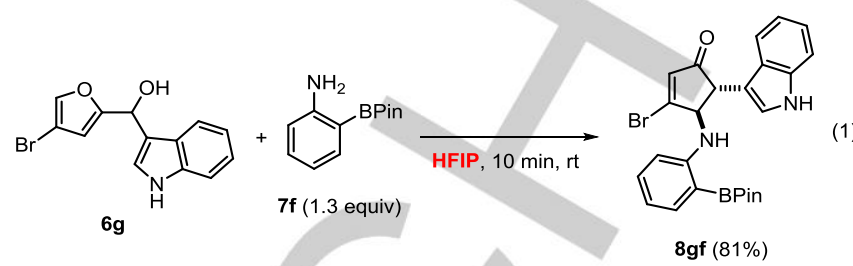

Finally, we evaluated the possibility of taking advantage of the alkene moiety of the 4-aminocyclopentenone to implement a Diels-Alder reaction and, thus, build the 5-6-5 aza-tricyclic core of gracilamine in a single step. To fulfil this goal, we prepared an aniline derivative incorporating a furan moiety $(\mathbf{7 g})$, which is a well-established diene system for Diels-Alder processes. To our surprise, in contrast with precedent reports,,$^{[13 f-g]}$ we did not obtain the classic Diels-Alder adduct, forming instead tetrahydro-1 $\mathrm{H}$ indene 13 in 90\% yield in HFIP (Scheme 6). This reactivity was also extended to 1,3-dienes to furnish the corresponding skeleton 14 in a good yield (65\%) under identical reaction conditions. ${ }^{[25]}$ To account for the formation of such products, we hypothesized that, following the aza-Piancatelli cyclization and the Diels-Alder reaction, the amine might be protonated under the highly acidic reaction conditions and a subsequent Ei elimination would take place.
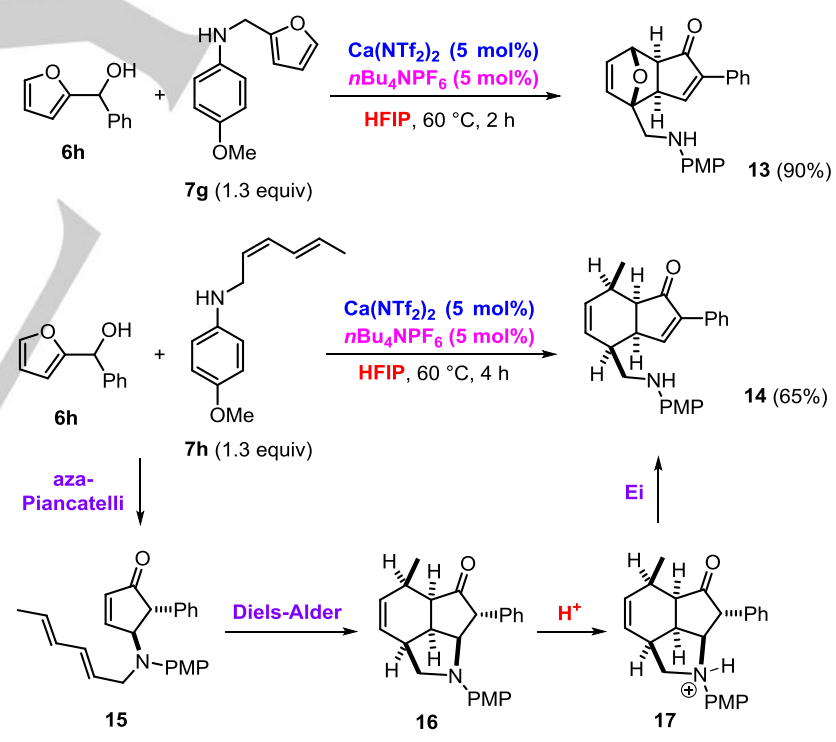

Scheme 6. Aza-Piancatelli/Diels-Alfer/fragmentation reaction sequence.

In conclusion, we have demonstrated that the aza-Piancatelli cyclization could be used successfully to access densely decorated molecules that closely resemble natural and bioactive molecules. It was notably showcased by the concise total synthesis of bruceolline $D$, which was achieved in 3 steps with $29 \%$ overall yield. More importantly, we gained a better insight into the group functional tolerance of this transformation and the influence of solvent on it, which should pave the way for its increasing utilization in total synthesis.

\section{Acknowledgements}


We gratefully thank the Ministère de l'Enseignement Supérieur et de la Recherche (funding for LM), the ANR (ANR-16-CE07-0022 funding for GF), the CNRS and Université Paris-Saclay for the support of this work.

Keywords: aza-Piancatelli $\bullet$ bruceolline D • electrocyclization • Lewis acid $\cdot$ natural products

[1] For recent reviews, see: a) C. Piutti, F. Quartieri, Molecules 2013, 18, 12290-12312; b) C. Verrier, S. Moebs-Sanchez, Y. Queneau, F Popowycz, Org. Biomol. Chem. 2018, 16, 676-687; c) R. F. A. Gomes, J. A. S. Coelho, C. A. M. Afonso, Chem. Eur. J. 2018, 24, 9170-9186.

[2] A. Berecibar, C. Grandjean, A. Siriwardena, Chem. Rev. 1999, 99, 779 844

[3] For the isolation of pactamycin, see: a) A. D. Argoudelis, H. K. Jahnke, J. A. Fox, Antimicrob. Agents Chemother. 1962, 191-197. For total syntheses of pactamycin, see: b) S. Hanessian, R. R. Vakiti, S. Dorich S. Banerjee, F. Lecomte, J. R. Del Valle, J. Zhang, B. Deschenes-Simard, Angew. Chem. Int. Ed. 2011, 50, 3497-3500; c) S. Hanessian, R. Vakiti, S. Dorich, S. Banerjee, B. Deschenes-Simard, J. Org. Chem. 2012, 77 9458-9472; d) J. T. Malinowski, R. J. Sharpe, J. S. Johnson, Science 2013, 340, 180-182; e) R. J. Sharpe, J. T. Malinowski, J. S. Johnson, J. Am. Chem. Soc. 2013, 135, 17990-17998. For a recent review on the strategies for the syntheses of pactamycin and jogyamycin, see: f) N. C Gerstner, K. A. Nistri, J. M. Schomaker, Angew. Chem. Int. Ed. 2020 doi: 10.1002/anie.202004560

[4] For the isolation of jogyamycin, see: a) M. Iwatsuki, A. NishiharaTsukashima, A. Ishiyama, M. Namatame, Y. Watanabe, S. Handasah, H. Pranamuda, B. Marwoto, A. Matsumoto, Y. Takahashi, K. Otoguro, S. Ömura, S. J. Antibiot. 2012, 65, 169-171. For synthetic efforts towards the synthesis of jogyamycin, see: b) N. C. Gerstner, C. A. Adams, R. D. Grigg, M. Tretbar, J. W. Rigoli, J. M. Schomaker, Org. Lett. 2016, 18 284-287; c) B. M. Trost, L. Zhang, T. M. Lam, Org. Lett. 2018, 20, 3938 3942; d) N. C. Gerstner, J. M. Schomaker, J. Org. Chem. 2019, 84, 14092-14100.

[5] For the biological activity of peramivir, see: a) C. E. Mancuso, M. P. Gabay, L. M. Steinke, S. J. Van Osdol, Ann. Pharmacother. 2010, 44 1240-1249. For total syntheses of peramivir, see: b) Y. S. Babu, P Chand, S. Bantia, P. Kotian, A. Dehghani, Y. El-Kattan, T. H. Lin, T. L. Hutchison, A. J. Elliott, C. D. Parker, S. L. Ananth, L. L. Horn, G. W. Laver, J. A. Montgomery, J. Med. Chem. 2000, 43, 3482-3486; b) T. Mireno, M. J. Miller, J. Org. Chem. 2003, 68, 6591-6596; c) F. Jia, J. Hong, P.-H. Sun, J.-X. Chen, W.-M. Chen, Synth. Commun. 2013, 43 2641-2647.

[6] For the isolation of trehazolin, see: a) O. Ando, H. Satake, K. Itoi, A. Sato, M. Nakajima, S. Takahashi, H. Haruyama, Y. Ohkuma, T. Kinoshita, R. Enokita, J. Antibiot. 1991, 44, 1165-1168. For total syntheses of trehazolin, see: b) Y. Kobayashi, H. Miyazaki, M. Shiozaki, J. Am. Chem. Soc. 1992, 114, 10065-10066; c) C. Uchida, T. Yamagishi, S. Ogawa, J Chem. Soc., Perkin Trans. 1 1994, 589-602; d) B. E. Ledford, E. M. Carreira, J. Am. Chem. Soc. 1995, 117, 11811-11812.

[7] For the isolation of cephalotaxine, see: a) W. W. Paudler, G. I. Kerley, J. McKay, J. Org. Chem. 1963, 28, 2194-2197. For the first total synthesis of cephalotaxine, see: b) J. Auerbach, S. M. Weinreb, J. Am. Chem. Soc 1972, 94, 7172-7173. For a review on cephalotaxine syntheses, see: c) H. Abdelkafi, B. Nay, Nat. Prod. Rep. 2012, 29, 855-869. For recent total syntheses of cephalotaxine, see: d) H. Liu, J. Yu, X. Li, R. Yan, J.-C Xiao, R. Hong, Org. Lett. 2015, 17, 4444-4447; e) X.-Y. Ma, X.-T. An, X.H. Zhao, J.-Y. Du, Y.-H. Deng, X.-Z. Zhang, C.-A. Fan, Org. Lett. 2017 19, 2965-2968; f) X. Ju, C. M. Baudry, Angew. Chem. Int. Ed. 2019, 58, $6752-6755$.

[8] For the isolation of bruceolline D, see: a) Y. Ouyang, K. Koike, T. Ohmoto, Phytochemistry 1994, 37, 575-578. For total syntheses of bruceolline D, see: b) J. M. Lopchuk, I. L. Green, J. C. Badenock, G. W Gribble, Org. Lett. 2013, 15, 4485-4487; c) X. Chen, H. Fan, S. Zhang C. Yu, W. Wang, Chem. Eur. J. 2016, 22, 716-723; d) D. H. Dethe, B. V. Kumar, Org. Chem. Front. 2015, 2, 548-551.

[9] For the isolation of yuehchukene, see: a) Y.-C. Kong, K.-F. Cheng, R. C. Cambie, P. G. Waterman, J. Chem. Soc., Chem. Commun. 1985, 47-48. For total syntheses of yuehchukene, see: b) K.-F. Cheng, Y.-C. Kong, T. Y. Chan, J. Chem. Soc., Chem. Commun. 1985, 48-49; c) J.-H. Sheu, Y.-K. Chen, H.-F. Chung, S.-F. Lin, P.-J. Sung, J. Chem. Soc., Perkin
Trans. 1 1998, 1959-1966; d) M. Ishikura, K. Imaizumi, N. Katagiri, Hetrocycles 2000, 53, 553-556.

[10] For the isolation of gracilamine, see: a) N. Unver, G.I. Kaya, Turk. J. Chem. 2005, 29, 547-553. For selected total syntheses of gracilamine, see: b) S. Tian, W. Zi, D. Ma, Angew. Chem. Int. Ed. 2012, 51, 10141 10144; c) Y. Shi, B. Yang, S. Cai, S. Gao, Angew. Chem. Int. Ed. 2014 53, 9539-9543; d) P. Gan, M. W. Smith, N. R. Braffman, S. A. Snyder Angew. Chem. Int. Ed. 2016, 55, 3625-3620; e) N. Gao, M. G. Banwell A. C. Willis, Org. Lett. 2017, 19, 162-165; f) M. Odagi, Y. Yamamoto, K. Nagasawa, Angew. Chem. Int. Ed. 2018, 57, 2229-2232. For a review on the total synthesis of gracilamine, see also: Y. Shi, H. He, S. Gao, Chem. Commun. 2018, 54, 12905-12913.

[11] V. R. Denisov, S. E. Shustitskaya, M. G Karpov, Zh. Org. Khim. 1993, 29, 249-252.

[12] G. K. Veits, D. R. Wenz, J. Read de Alaniz, Angew. Chem. Int. Ed. 2010 , 49, 9484-9487.

[13] For sequential reactions featuring an aza-Piancatelli cyclization, see: a) B. V. S. Reddy, Y. V. Reddy, P. S. Lakshumma, G. Narasimhulu, J. S Yadav, B. Sridhar, P. P. Reddy, A. C. Kunwar, RSC Adv. 2012, 2, 1066110666; b) D. R. Wenz, J. Read de Alaniz, Org. Lett. 2013, 15, 3250-3253 c) B. V. S. Reddy, Y. V. Reddy, K. Singarapu, Org. Biomol. Chem. 2016 14, 1111-1116; d) K. Nayani, R. Cinsani, A. Hussaini SD, P. S. Mainkar, S. Chandrasekhar, Eur. J. Org. Chem. 2017, 5671-5678; e) Z. Wei, J. Zhang, H. Yang, G. Jiang, Org. Lett. 2019, 21, 2790-2794; f) S. Gouse N. R. Reddy, S. Baskaran, Org. Lett. 2019, 21, 3822-3827; g) B. Shen Q. He, S. Dong, X. Liu, X. Feng, Chem. Sci. 2020,11, 3862-3867.

[14] a) L. Marin, V. Gandon, E. Schulz, D. Lebœuf, Adv. Synth. Catal. 2017, 359, 1157-1163; b) L. Marin, R. Guillot, V. Gandon, E. Schulz, D. Lebœuf, Org. Chem. Front. 2018, 5, 640-647.

[15] B. Baldé, G. Force, L. Marin, R. Guillot, E. Schulz, V. Gandon, D. Lebœuf, Org. Lett. 2018, 20, 7405-7409.

[16] S. Wang, R. Guillot, J.-F. Carpentier, Y. Sarazin, C. Bour, V. Gandon, D. Lebœuf, Angew. Chem. Int. Ed. 2020, 59, 1134-1138.

[17] D. Lebœuf, E. Schulz, V. Gandon, Org. Lett. 2014, 16, 6464-6467.

[18] D. W. Knight, A. P. Nott, J. Chem. Soc., Perkin Trans. 1, 1981, 11251131.

[19] D. Lebœuf, L. Marin, B. Michelet, A. Perez-Luna, R. Guillot, E. Schulz, V. Gandon, Chem. Eur. J. 2016, 22, 16165-16171.

[20] For reviews on HFIP, see: a) J.-P. Bégué, D. Bonnet-Delpon, B. Crousse Synlett 2004, 18-29; b) I. A. Shuklov, N. V. Dubrovina, A. Börner Synthesis 2007, 2925-2943; c) T. Sugiishi, M. Matsugi, H. Hamamoto, H. Amii, RSC Adv. 2015, 5, 17269-17282; d) J. Wencel-Delord, F. Colobert Org. Chem. Front. 2016, 3, 394-400; e) I. Colomer, A. E. R. Chamberlain M. B. Haughey, T. J. Donohoe, Nat. Rev. Chem. 2017, 1, 0088; f) S. K. Sinha, T. Bhattacharya, D. Maiti, React. Chem. Engl. 2019, 4, 244-253.

[21] A. G. Volbeda, H. A. V. Kistemaker, H. S. Overkleeft, G. A. van der Marel, D. V. Filippov, J. D. Codée, J. Org. Chem. 2015, 80, 8796-8806.

[22] Of note, regarding the synthesis of analogues of pactamycin, functionalities other than benzyl were also tested in model substrates but did not lead to the corresponding 4-aminocyclopentenones:

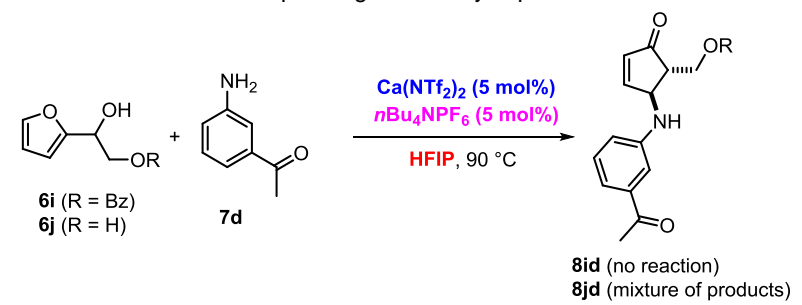

[23] We also envisaged another strategy involving a Heck cross-coupling reaction; however, we did not pursue this idea as the cyclization between precursor $\mathbf{6 f}$ and 2-iodoaniline did not give satisfactory yields $(<30 \%)$.

[24] V. Magné, C. Lorton, A. Marinetti, X. Guinchard, A. Voituriez, A. Org. Lett. 2017, 19, 4794-4797.

[25] The structural arrangement of compounds 13 and 14 was ascertained by NOESY experiments (See the SI for details). 


\section{Entry for the Table of Contents}

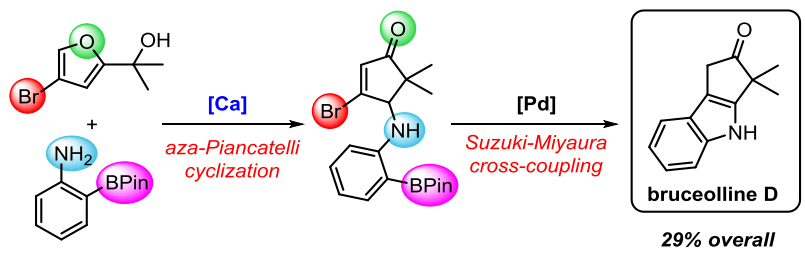

Insert text for Table of Contents here.

Institute and/or researcher Twitter usernames: @djpleboeuf 